\title{
PROBLEMS OF INTERNATIONAL CONCERN IN THE BIOLOGICAL SCIENCES
}

$\mathrm{D}^{\mathrm{s}}$ URING the 'Twelfth General Assembly of the International Union of Biological Sciences, held in Rome in the rooms of the Consiglio Nazionale delle Ricerche during April 12-16, a symposium was held on "Problems of International Concern in the Biological Sciences" with the aim of discussing some possible lines for the future work of the Union. The symposium was centred around seven major topics, and the discussion of each was introduced by a panel of three. In each panel one of the three acted as the chairman of the discussion.

For the first topic, "Standards, Units, Symbols and Terms", A. Frey-Wyssling (Botanisches Institut, Zurich) was chairman, and J. H. Burn (Department of Pharmacology, Oxford) and E. Hadorn (Zoologisches Institut, Zurich) were the main speakers. It was recommended that the Union should urge the universal adoption of the decimal system for international scientific publications: editors of international periodicals should be requested to convert all units into the decimal system if the authors had not already done so. A more general resolution aiming at promoting the unification of standards, units, symbols and terms in the field of biology was adopted by the General Assembly. Dr. Burn discussed the successive steps in the co-ordination of international standards for substances demanding biological assay. The matter is now regulated by an organization established under the auspices of the United Nations World Health Organization, which is working well. Dr. Hadorn's speech was especially concerned with the work of the Committee on Genetical Nomenclature and Symbols. It is planned to have a conference on this topic immediately before the next International Congress of Genetics, which is to be held in Montreal during 1958.

The second topic dealt with the "Organization and Support of Research", with R. E. Cleland (Botanical Institute, Bloomington, Ind.) as chairman, and C. F. A. Pantin (Zoological Laboratory, Cambridge) and B. Rajewsky (Max-Planck-Institut, Frankfurt-am-Main) as main speakers. The matter was thoroughly discussed, and finally it was suggested that the International Union of Biological Sciences should attempt four things: to persuade countries to undertake co-operative solutions of problems which transcend national boundaries; to make pronouncements on matters of world-wide scientific concern where the welfare of science is threatened by considerations involving the interests of individual nations; to organize programmes of rəsearch which cannot be organized by individual nations; to devote some of its time to the consideration of future trends in biology, and of how certain major problems of biologists, such as publishing, can be solved in the future (to this end the Union might sponsor symposia from time to time on such topics, either at the time of the General Assembly, or independently).

The third topic, "Teaching and Training", was introduced by $\mathrm{P}$. Weiss (Rockefeller Institute, New York). The invited speakers were Chr. P. Raven (Zoologisches Laboratorium, Utrecht) and W. Ankel
(Zoologisches Institut, Giessen). The discussion centred around the dilemma, clearly pointed out by Weiss, that, on one hand, biology has developed from many independent branches which are gradually discovering their common principles, thus calling for a deliberate integration; and, on the other, that the increasing volume of biological research and the spectacular advances in certain lines are fostering a dispersive tendency toward further fragmentation. The rate of progress in the biological sciences will depend to a great extent on the rate at which biological teaching can be made to cope with these conflicting trends and adapt itself to the changing situation. Students should be prepared for the biology of the future rather than educated in that of the past.

The subject of the fourth topic was "Publications", and for this M. J. Sirks (Genetisch Institut, Haren) was chairman, with B. Glass (Department of Biology, Baltimore, Md.) and P. Rosbaud (Pergamon Press, Ltd., London) as panel members. The international support of periodicals should go first to the abstracting and indexing periodicals; second, to review periodicals and book series; third, to handbooks of data, indexes, lists of materials and workers, dictionaries of symbols, etc.; and lastly, to monographs of a costly and truly international scope.

In view of the magnitude of the literature to be surveyed, the abstracting and indexing journals must begin to co-operate and co-ordinate their efforts. It was recommended that they apply for admission to the Abstracting Board of the International Council of Scientific Unions and that they work out a cooperative plan. Since both general and specialized abstracting periodicals are for the present necessary, the latter should provide the former with a selected coverage of special fields, and each of the former should undertake to cover completely a nucleus of journals not dealt with by the other general abstracting services. Review periodicals and book series should be subsidized so far as possible in order to reduce their present high cost to users throughout the world. Co-ordination should be developed to prevent simultaneous reviews of the same subject in different places.

The recommendations to the Executive Committee of the International Union of Biological Sciences with regard to the fifth topic of the symposium, "Supplies and Depositories" (Dr.L. Harrison Matthews (Zoological Society, London) chairman, with A. van Straelen (Museum of Natural History, Brussels) and J. Westerdijk (Centraalbureau voor Schimmelcultures, Baarn) as panel members), were threefold. Living materials. The appointment of a small international committee to study the problems of the supply of laboratory animals, the cataloguing of users and of sources of supplies, the definition of standards and related matters on an international scale; representatives of the Division of Botany and of the Sections of Microbiology and Genetics should be included in the committee to advise upon the matters relating to their subjects. Museum collections. While the documentation of botanical type specimens 
appears to be satisfactorily in progress, the same cannot be said for zoological type specimens. It might be useful to ask a small panel of zoologists to draw up recommendations for the preservation, collection and cataloguing of zoological type specimens, the distribution of co-types and para-types, and the safeguarding of the type specimens in times of international emergency. International expeditions. Unesco should be advised when international expeditions are under consideration, both for the selection of personnel and for the distribution of specimens collected.

The ehairman for the sixth topic, "International Congresses and Conferences", was J. Runnström (Wenner Grens Institutet, Stockholm), and the invited speakers were Sir Gavin de Beer (British Museum (Natural History), London) and P. Chouard (Conservatoire National des Arts et Métiers, Paris). The main conclusions of the discussion of this very important topic were as follows. The large international congresses should not be suppressed; their need is still very great in the biological sciences to avoid the danger of over-specialization. Their rhythm should be one of four or five years. The congresses should include a number of symposia introduced by at least two invited speakers with divergent views or with a divergent approach to the subject. Discussion from the floor should be allowed after the introductory papers. Uninvited short papers should be submitted to previous scrutiny, as is customary for the acceptance of a paper in a scientific journal. It was also decided that specialized conferences (symposia) with no more than twenty to twenty-five participants should be held between the general congresses. The Executive Committee of the Union should study the question of publication of the proceedings of the symposia in order to reach a certain degree of uniformity.

The last topic of the symposium, which dealt with "International Co-operative Projects", should have been introduced by B. Rensch (Zoologisches Institut, Münster), but he was unfortunately not able to attend, and J. Runnström took the chair in his place; Dr. Rensch's paper was read by Dr. I. Harrison Matthews (London). R. Hiatt (Hawaii Marine Laboratory, Honolulu) and E. Aichinger (Landesinstitut für Pflanzensociologie, St. Georgen am Sandhof, Austria) were the two invited speakers; but the latter was absent. Rensch expressed the opinion that the barriers raised by differences in language are greater than they should be, and that more personal contact would help to remove these hindrances to the more complete utilization of scientific experience. In some fields of biological research, international co-operation is imperative : such are the biological problems presented, for example, by the oceans and the polar regions. International co-operation is also essential within certain borderline fields between biology and other sciences, as, for example, biometry, biophysics and biological philosophy. Hiatt's special concern was international co-operative projects in marine biology ; this matter was more exhaustively discussed in a symposium on marine biological laboratories held under the auspices of the Union a week later (se日 Nature, June 18, p. 1062).

In conclusion, it may be said that many of the resolutions or suggestions which came out of the discussion at the symposium were adopted by the General Assembly of the International Union of Biological Sciences, or will guide the future policy of the Executive Committee of the Union.

\section{BREEDING LABORATORY ANIMALS}

$T^{n}$ THE use of laboratory animals in nearly all branches of biological research has been steadily increasing for several decades and, as was to be expected, it has kept in step with the general increase in work of this kind. Moreover, the usefulness of animals, and in particular of the smaller mammals such as the common laboratory rodents, in investigating and assaying drugs and other therapeutic substances not susceptible to chemical standardization accounts to-day for a very large proportion of all laboratory animals used in Britain and in most other countries ${ }^{1}$. Concomitant with this increased use has developed the demand for quality, so that to-day laboratory animals tend to be regarded more or less as reagents. Among the essential qualities of any reagent are some indication of its purity, or at least its degree of contamination, and also the requirement that it should be perennially reproducible. This implies that attention must be given to the methods of producing these biological reagents ${ }^{2}$.

In the past much reliance has been placed upon animals supplied by breeders or dealers whose main interest is to offer suitable animals for sale upon such terms as will afford them reasonable business profits. There is much to be said for this system in that it relieves laboratory workers of the burden of manufacturing their own reagents, and, provided the quality of the animals supplied in this way is of a high enough standard, there is every reason to suppose that the commercial breeder or supplier will remain in the field indefinitely.

This proviso, however, is an important one, because to-day the laboratory worker's demands for animals of a given specification are more exacting than ever before. For certain types of animal, commercial sources cannot hope to provide suitable material, and the laboratory worker is driven, often rather reluctantly, to breed his own animals. Such instances as inbred strains of mice for cancer research, and the production of litter-mate groups, may be cited. It has now become quite evident that, in order to obtain animals of the quality required, it is often necessary to breed them under laboratory conditions and in considerable numbers-numbers such as will satisfy the greater part of the demands of, say, all the laboratories of a single university.

It was therefore timely that a symposium on the breeding of laboratory animals should have been arranged by the Laboratory Animals Bureau, and was held at the Royal Society of Medicine on May 9, with Prof. E. C. Amoroso, of the Royal Veterinary College, London, in the chair. The papers read at the symposium will be published in the "Collected Papers", Vol. 3, of the Laboratory Animals Bureau (obtainable from the M.R.C. Laboratories, Holly Hill, Hampstead, London, N.W.3).

Mr. A. L. Bacharach (Glaxo Laboratories, Ltd.) opened the symposium with a paper entitled "Some Aspects of Animal Production for Routine Biological Assay". He treated his subject mainly from the point of view of the user, and he drew largely from his experience of the colonies of rats and mice which have been maintained for many years by the Glaxo Laboratories at Greenford. These colonies were set up in order to fulfil the exacting demands of the bio-assayists, and Mr. Bacharach played a prominent part in their establishment. Experience at Greenford 